\title{
Myxobolus lentisuturalis sp. n. (Myxozoa: Myxobolidae), a new muscle-infecting species from the Prussian carp, Carassius gibelio from China
}

\author{
Iva Dyková ${ }^{1,2}$, Ivan Fiala ${ }^{1,2}$ and Pin Nie ${ }^{3}$ \\ ${ }^{1}$ Institute of Parasitology, Academy of Sciences of the Czech Republic, Branišovská 31, 37005 České Budějovice, Czech \\ Republic; \\ ${ }^{2}$ Faculty of Biological Sciences, University of South Bohemia, Branišovská 31, 37005 České Budějovice, Czech Republic; \\ ${ }^{3}$ State Key Laboratory of Freshwater Ecology and Biotechnology and Laboratory of Fish Diseases, Institute of Hydrobiology, \\ Chinese Academy of Sciences, Wuhan 430072, Hubei Province, P. R. China
}

Key words: Myxozoa, Myxobolidae, new species, morphology, SSU rDNA

\begin{abstract}
A new highly pathogenic muscle-infecting species of the genus Myxobolus Bütschli, 1882 is described from the Prussian carp, Carassius gibelio (Bloch, 1782) using spore morphology and SSU rDNA sequence data. Phylogenetic analyses elucidated relationship of the newly described Myxobolus lentisuturalis to other Myxobolus species and supported its position of an independent species.
\end{abstract}

After a revision of synonyms, more than four hundred (453) named species were listed within the genus Myxobolus Bütschli, 1882 by Landsberg and Lom (1991). Since then the number of recognised species of the genus has grown, most of the species being distinguished from each other solely on morphological criteria. Of all species described to date within the genus Myxobolus, thirty only have been characterised also with molecular data, using sequences of SSU rDNA. In the recent review of advances in the understanding of Myxozoa, Kent et al. (2001) stated that molecular data that they used as the basis for conclusions on evolutionary relationships among the Myxozoa were limited and appealed to researchers to extend them. In accordance with the authors of that key review we believe that the only valuable molecular data are those obtained for morphologically well-described species. Unfortunately, spores of many species of the genus Myxobolus are very similar to each other, many published descriptions are incomplete or not explicit and many are inconsistent with their documentation. Among hundreds of named species, a small number only is documented by photomicrographs. Inconsistencies in line drawings of the same species produced by different authors make the species identification of new findings sometimes extremely difficult.

In this communication we present a description of a new species of Myxobolus coupled with sequence information for SSU rDNA and phylogenetic analyses of molecular data.

\section{MATERIALS AND METHODS}

In 5 out of 25 specimens of Carassius gibelio (Bloch, 1782) (size range 12.0-16.5 cm) collected in September 2001 from Lake Bao'an in Hubei Province, China, mutually identical spores of the genus Myxobolus Bütschli, 1882 were found. In one fish the infection was manifested by gross deformity, a hump anterior to the dorsal fin. The lesion, limited to skeletal muscles, contained a mass of mature spores. They were cleaned from tissue debris by washing in an ample volume of sterile distilled water and used for morphological and molecular characterisation. Following Lom and Arthur's (1988) guidelines, the measurements of spores were taken with a calibrated eyepiece micrometer and also with image analytical software (analySIS ${ }^{\circledR}$, Soft Imaging System GmbH, Germany). Tissue samples were fixed in modified Davidson's fixative and processed for histology using Histowax (Reichert Jung) as an embedding medium. Histological sections were stained with haematoxylin and eosin (H\&E) and Giemsa stains.

Total cell DNA was extracted from spores using the DNeasy ${ }^{\mathrm{TM}}$ Tissue Kit (Quiagen, Germany) according to the manufacturer's protocol. The SSU rRNA gene was PCRamplified with a set of universal eukaryotic primers (5'AYCTGGTTGATYYTGCCAG-3' and 5'-TGATCCATC TGCAGGTTCACCT-3') (Embley et al. 1992). PCR was carried out in a $25-\mu 1$ reaction volume using $10 \mathrm{pmol}$ of each primer, $250 \mu \mathrm{M}$ of each dNTP, and $2.5 \mu 110 \times$ PCR Buffer (Takara, Japan) and 1 unit of TaqDNA polymerase (Takara, Japan). The reactions were run on a T3 Thermocycler (Biometra). Conditions were as follows: initial denaturation at $95^{\circ} \mathrm{C}$ for $5 \mathrm{~min}$ followed by 30 cycles at $94^{\circ} \mathrm{C}$ for $1 \mathrm{~min}$, at $48^{\circ} \mathrm{C}$ for $2 \mathrm{~min}$, at $72^{\circ} \mathrm{C}$ for $2 \mathrm{~min}$ and a final extension at 
$72^{\circ} \mathrm{C}$ for $10 \mathrm{~min}$. Amplification products were gel-isolated and cloned into $\mathrm{pCR}^{\circledR} 2,1$ TOPO Cloning vector using the TOPOTA Cloning Kit (Invitrogen). They were sequenced from both strands on an automatic sequencer $\mathrm{CEQ}^{\mathrm{TM}} 2000$ (Beckman Coulter) using CEQ DTCS Dye Kit (Beckman Coulter) according to the manufacturer's protocol.

The SSU rRNA gene sequences were aligned using Clustal $X$ program (Thompson et al. 1997) with various alignment parameters. In order to identify the most accurate position of $M$. lentisuturalis in the myxosporean tree, the dataset of sequences covering maximum of myxosporean species available in GenBank was used for the first alignment. Polypodium hydriforme, a parasitic narcomedusan, was chosen as outgroup. The alignment was corrected by eye using the BioEdit sequence alignment editor (Hall 1999). Ambiguously aligned regions were excluded. The second alignment included sequences of species related to M. lentisuturalis. Ceratomyxa shasta, Myxidium truttae and Myxidium sp. (Accession No. U13829) were selected as outgroups based on results from analysis of the first alignment. Phylogenetic analyses were performed using maximum parsimony (MP) and distance methods (minimum evolution). Methods were carried out with the program package PAUP*, Version 4.0b8a (Swofford 2001). The MP analysis was done using heuristic search with random addition of taxa (10 replications) and the ACCTRANoption. Gaps were treated as missing data and transversion/transition (Tv/Ts) ratios of $1: 1,1: 2,1: 3$ and $1: 4$. The distance method was executed using heuristic search with the minimum evolution as the objective setting. We used K2P and GTR substitution models. Genetic distances were calculated with K2P algorithm. Clade support was assessed with bootstrapping (500 replicates for MP, 1000 replicates for distance method).

\section{RESULTS}

\section{Myxobolus lentisuturalis sp. $\mathrm{n}$.}

Figs. 1-3

Description of fresh spores (light microscopy). Spores (Figs. 1-3) ellipsoidal, 11.8 (11.2-12.4) $\mu \mathrm{m}$ long, $7.6(7.2-8.4) \mu \mathrm{m}$ wide and $5.2 \mu \mathrm{m}$ thick $(\mathrm{n}=20)$. Results of image analysis: $\mathrm{L}=11.82 \pm 0.36$, median 12 ; $\mathrm{W}=7.64 \pm 0.30$, median 7.6. Mucus envelope lacking. Shape of spores uniform (Figs. 2, 3). Two equal-sized pyriform polar capsules 4.2 (4.0-4.4) $\mu \mathrm{m}$ long $\times 2.5$ $(2.0-2.8) \mu \mathrm{m}$ wide, with long axes parallel to long axis of spore. Posterior end of polar capsules slightly exceeding mid-spore length, (ratio 1.16). Thickening of apical part of suture bulges inwards and separates points of polar capsules at a distance of 2.4-2.8 $\mu \mathrm{m}$. Polar filaments coiled four times. Sutural folds very difficult to discern. Of the features discriminating Myxobolus lentisuturalis from other species with similar shape of spores, the most important was the position of polar capsules as seen in frontal view (Figs. 1-3).

T y p e h o st: Carassius gibelio (Bloch, 1782) (Cypriniformes, Cyprinidae).

$\mathrm{S}$ i t e of infection: Muscle tissue (m. laterodorsalis). Plasmodia developed in muscle fibres (Fig. 4).

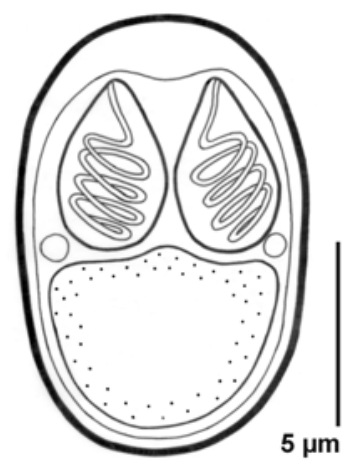

Fig. 1. Myxobolus lentisuturalis sp. n., frontal view of a mature spore.

Ty pe loc a lity: Lake Bao'an, Hubei Province, China.

P r e v a 1 e $n$ c e : Five of 25 fish examined (20\%) were infected.

T y p e $\mathrm{m}$ a t e r i a 1 : Slides with stained spores are deposited in the Institute of Parasitology, Academy of Sciences of the Czech Republic, České Budějovice (Cat. Nos. H-PM-060 to 063) and in the Institute of Hydrobiology, Chinese Academy of Sciences, Wuhan, P. R. China.

$\mathrm{E} \mathrm{t}$ y $\mathrm{m} \mathrm{o} 1 \mathrm{og} \mathrm{y}$ : The name is derived from a conspicuous morphological feature, lens-like thickening of the valve suture bulging inwards and separating points of polar capsules. (Lens, genit. lentis, Latin, a lens.)

SSU rDNA sequence data and phylogenetic analyses

The length of complete sequence of $M$. lentisuturalis was $2107 \mathrm{bp}$ including regions corresponding to forward and reverse primers. $\mathrm{G}+\mathrm{C}$ content was 47.7 . The sequence was deposited in the GenBank under accession number AY119688. The phylogenetic analyses were based on a final alignment (2217 nucleotide sites) consisting of 49 taxa, from which ambiguously aligned areas (240 nucleotide sites) were removed. The dataset for this alignment was chosen upon the preliminary results based on the first alignment and consisted of Myxobolus-related species. The most closely related species shown by the SSU rRNA gene analyses were Myxobolus xiaoi and Myxobolus sp. from Catostomus commersoni (Acc. No. AF378343). The distances computed from the alignment revealed $91.4 \%$ and $91.8 \%$ similarity between $M$. lentisuturalis and two sequences of M. xiaoi. Myxobolus sp. (Acc. No. AF378343) from Catostomus commersoni was $88.2 \%$ similar to $M$. lentisuturalis. The similarity to other myxosporean species was about $70 \%$.

Myxobolus lentisuturalis clusters with the freshwater clade of myxosporeans represented mostly with Myxobolus and Henneguya species. In all performed analyses ( $\mathrm{MP}-\mathrm{Tv} / \mathrm{Ts}=1: 1,1: 2,1: 3,1: 4$ and distance methods) this clade consisted of three well-supported subclades corresponding to previous studies (Kent et al. 2001). The subclade containing $M$. lentisuturalis included other Myxobolus species (e.g., M. cerebralis) and also Sphaerospora truttae and two species of Henneguya. 


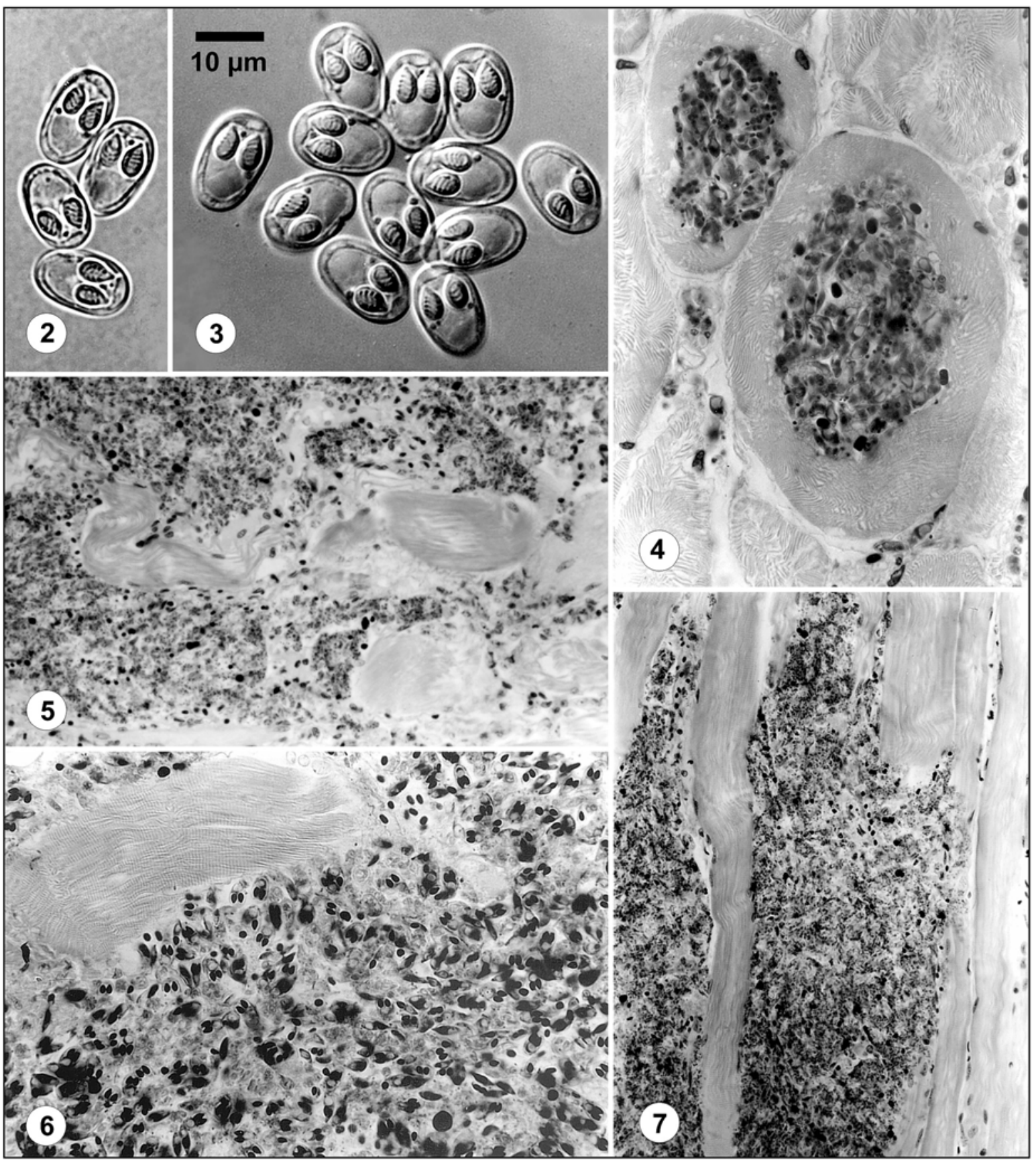

Figs. 2, 3. Myxobolus lentisuturalis sp. n., mature spores. Fig. 2. Spores as seen in translucent light. Fig. 3. Spores as seen in Nomarski differential interference contrast. Fig. 4. Plasmodia of M. lentisuturalis developing within muscle fibres, H\&E, $\times 650$. Figs. 5-7. Histopathological changes including atrophy and necrosis induced by M. lentisuturalis in muscle tissue of Prussian carp. Figs. 5 and 7, H\&E, $\times 240$. Fig. 6, Giemsa staining, $\times 425$.

Myxobolus lentisuturalis constitutes a strongly supported clade with M. xiaoi and Myxobolus sp. from $C$. commersoni (Fig. 8). The ancestral position of M. lentisuturalis that resulted from MP with Tv/Ts $=1: 2$ (three most parsimonious trees, 9669 steps) was weakly sup- ported (57\%), but this topology remained unchanged in MP with $\mathrm{Tv} / \mathrm{Ts}=1: 3$ (18 most parsimonious trees, 12536 steps) and 1:4 (six most parsimonious trees, 15395 steps). Distance method with K2P and GTR model of evolution and MP with TV/Ts $=1: 1$ (six most 


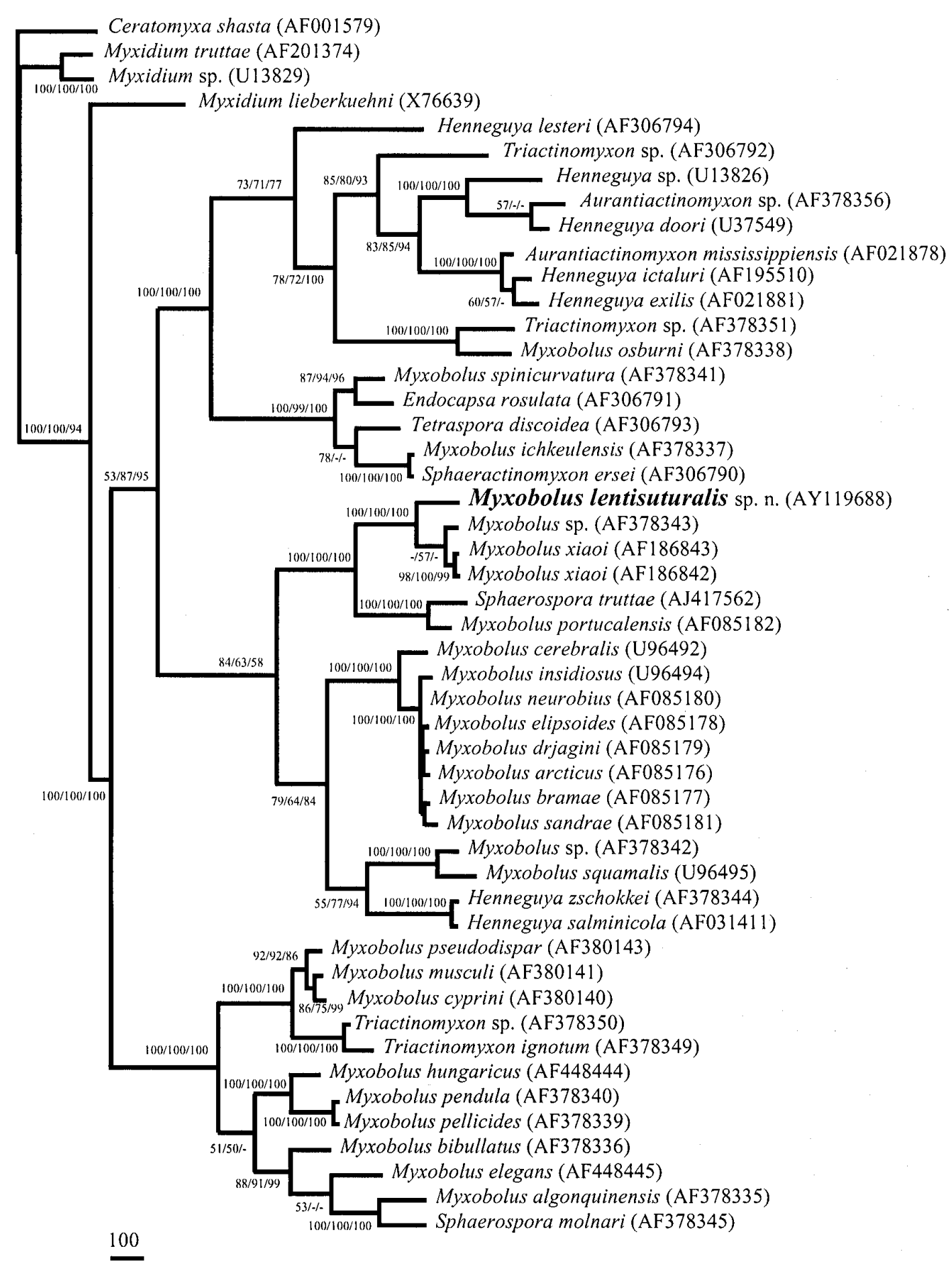

Fig. 8. Maximum parsimony tree of the SSU rRNA gene sequences of myxosporeans rooted at Ceratomyxa shasta, Myxidium truttae and Myxidium sp. (Tv/Ts = 1:2, 9669 steps). Bootstrap values (MP Tv/Ts = 1:1, MP Tv/Ts = 1:2, distance method K2P) are indicated for nodes gaining more than $50 \%$ support. GenBank accession numbers are in parentheses. The scale is given under the tree. 
parsimonious trees, 6787 steps) placed Myxobolus sp. (Acc. No. AF378343) in an ancestral position to $M$. lentisuturalis and M. xiaoi. Sphaerospora truttae and $M$. portucalensis branched as sister taxa to this group with $100 \%$ bootstrap support in all performed analyses.

\section{Pathogenicity}

Myxobolus lentisuturalis induced severe regressive changes in the dorsal muscle (m. laterodorsalis) anterior to the dorsal fin. In the most heavily infected fish the muscle tissue was transformed into a mash due to necrosis of infected muscle fibres (Figs. 5-7). Transverse sections through the fish body revealed that myonecrosis also afflicted deep epaxial musculature adjacent to vertebrae. In addition, mature spores accumulated in the connective tissue of myosepta and were found in melanomacrophage centres of parenchymatous organs as well as in gills, wall of intestine, the brain and gall bladder. Extramuscular findings of spores were product of spore dispersal. Host cellular reaction involved a mixture of macrophages and lymphocytes. No signs of demarcation were observed in heavily infected muscles. In the four other infected fish, the intensity of infection was low: small aggregations of spores were found in squash preparations of muscle tissue and individual spores were also found in other organs.

\section{DISCUSSION}

\section{Spore morphology}

In the recent book on Myxozoa which appeared in the series of Fauna Sinica (Chen and Ma 1998) the genera Myxosoma and Myxobolus are still separated; 269 Myxobolus species (including 129 new species) are reported to parasitise freshwater fishes in China. In total, 76 Myxosoma/Myxobolus species are included in the list as occurring in three host species of the genus Carassius (Bloch), the most numerous (65) being those found in C. auratus auratus (Linnaeus) (Chen and Ma 1998). According to Chen and Ma (1998), C. carassius and $C$. auratus gibelio (both inhabit also Lake Bao'an) host 12 species of Myxosoma and Myxobolus. Six of these are distinguished by round or almost round spores in frontal view (Myxosoma acuta Kudo, 1933; $M$. sphaerica Fujita, 1924; Myxobolus gibelioi Wu et Wang, 1998; M. dogieli I. et B. Bychowsky, 1940; M. pseudoparvus Li et Nie, 1973; and M. solidus Shulman, 1962 [all names as in Chen and Ma 1998]). Myxobolus bladderia Chen et Ma, 1998 has oval spores with pointed anterior end, M. dispar Thélohan, 1895 and $M$. chuhsienensis Chen et Ma, 1998 have nearly ovoid spores. Only three Myxobolus species of those listed by Chen and Ma (1998) for C. carassius and C. gibelio in China (Myxosoma/Myxobolus notropis Fantham, Porter et Richardson, 1939; Myxobolus carassii Klokačeva, 1914; and M. kubanicum I. et B. Bychowsky, 1940 [sic]) resemble, to some extent, the spores under study. Although similar in shape according to descriptions and some of the drawings available, their spores differ in diagnostic features. Spores of $M$. notropis are 13.7 (12.0-15.6) $\mu \mathrm{m}$ long, 8.6 (7.8-9.0) $\mu \mathrm{m}$ wide and have many sutural ridges. Spores of $M$. carassii, with the average length $(13.6 \mu \mathrm{m})$ exceeding the range of our material, have polar capsules with convergent anterior points and six to eight coils of polar filament. The measurements of spores in our material correspond with those given in the description of Myxobolus kubanicus Bykhovskaya-Pavlovskaya et Bykhovski, 1940, the species common for all Carassius hosts in China $(C$. auratus auratus, C. carassius and C. gibelio). Myxobolus kubanicus has been documented in a series of line drawings showing surprising variability of spores (Chen 1973, Shulman 1984, Zhang and Li 1990, Chen and Ma 1998). Since gross lesions induced by $M$. lentisuturalis were similar to those depicted in Chen and Ma (1998) for infection with $M$. carassii and $M$. kubanicus, we analysed carefully the descriptions and drawings of the latter species available in the literature (Shulman 1966, 1984, Chen 1973, Zhang and Li 1990, Chen and Ma 1998). Only one among twelve simplified line drawings of M. kubanicus resembles our spores, while triangular intercapsular processes, sutural ridges and convergent polar capsules of different size testify that $M$. kubanicus is a distinct species.

Among 65 Myxosoma and Myxobolus species listed for C. auratus auratus in Chen and Ma (1998), another four species (Myxosoma pfrille Fantham, Porter et Richardson, 1939; Myxobolus hypseleotris Chen, 1998; Myxobolus ochengensis Chen, 1998; and Myxobolus inflatus Chen, 1998) have similar shape of spores, but other features distinguish them from our material. The thickening of anterior part of spore suture is absent in all of them. In addition, the polar capsules of $M$. pfrille, $M$. hypseleotris and $M$. ochengensis are clearly convergent. Spores of $M$. inflatus have a relatively large intercapsular process with a narrow base.

Contrary to variability depicted for many species of the genus Myxobolus parasitising cyprinids, the uniformity of shape of spores of $M$. lentisuturalis was conspicuous, probably due to the fact that basically one infrapopulation was evaluated while from the other four host specimens only a small number of spores was available and used for study.

\section{Phylogenetic relationships}

In accordance with the recent review of Myxozoa (Kent et al. 2001) the freshwater clade of myxosporeans branched in our phylogenetic analyses into three wellsupported subclades. Kent et al. (2001) did not include in their phylogenetic analysis two partial sequences of M. xiaoi and the sequence of Sphaerospora truttae recently submitted to GenBank. Based on our results both species are closely related to $M$. lentisuturalis. The addition of three sequences changed the internal branching pattern of the subclade. Myxobolus lentisuturalis clustered with Myxobolus sp. from white sucker (Acc. 
No. AF378343) and with M. xiaoi. Henneguya zschokkei and $H$. salminicola clustered with $M$. squamalis and Myxobolus sp. from rainbow trout (Acc. No. AF 378342).

In conclusion, phylogenetic analyses show a clearly independent position of $M$. lentisuturalis among the Myxobolus species sequenced to date. Although to understand species-level boundaries is often difficult, the comparison with very weakly resolved $M$. cerebralis and closely related species allow us to consider $M$. lentisuturalis as an independent species.

Acknowledgements. The authors are grateful to the Ministry of Education, Youth and Sports of the Czech Republic for financial support of this research (Project KONTAKT ME 424 and Project No. MSM 12300003), and to the National Natural Science Foundation of China (Project No. 30025035).

\section{REFERENCES}

CHEN C. (Ed.) 1973: [An Illustrated Guide to the Fish Diseases and Causative Pathogenic Fauna and Flora in the Hubei Province.] Academia Sinica Press, Peking, 456 pp. (In Chinese.)

CHEN C., MA C. 1998: Fauna Sinica. Myxozoa, Myxosporea. Science Press, Beijing, China, 993 pp.

EMBLEY T.M., FINLAY B.J., THOMAS R.H., DYAL P.L. 1992: The use of rRNA sequences and fluorescent probes to investigate the phylogenetic positions of the anaerobic ciliate Metopus palaeformis and its archaeobacterial endosymbiont. J. Gen. Microbiol. 138: 1479-1487.

HALL T.A. 1999: BioEdit: a user-friendly biological sequence alignment editor and analysis program for Windows 95/98/NT. Nucl. Acids Symp. Ser. 41: 95-98.

KENT M.L., ANDREE K.B., BARTHOLOMEW J.L., ElMATBOULI M., DESSER S.S., DEVLIN R.H., FEIST S.W., HEDRICK R.P., HOFFMANN R.W., KHATTRA J., HALLET S.L., LESTER R.J.G., LONGSHAW M., PALENZUELA O., SIDDALL M.E., XIAO C. 2001: Recent advances in our knowledge of the Myxozoa. J. Eukaryot. Microbiol. 48: 395-413.

LANDSBERG J.H., LOM J. 1991: Taxonomy of the genera Myxobolus/Myxosoma group (Myxobolidae: Myxosporea), current listing of species and revision of synonyms. Syst. Parasitol. 18: 165-186.

LOM J., ARTHUR J.R. 1988: A guideline for the preparation of species description in Myxosporea. J. Fish Dis. 12: 151156.

SHULMAN S.S. 1966: [Myxosporidia of the Fauna of the USSR.] Nauka, Moscow, 504 pp. (In Russian.)

SHULMAN S.S. (Ed.) 1984: [Parasitic Protozoa Vol.1.] In: O.N. Bauer (Ed.), [Key to the Parasites of Freshwater Fauna of the USSR, Vol. 140] [Keys to the Fauna of the USSR]. Nauka, Leningrad, 428 pp. (In Russian.)

SWOFFORD D.L. 1998: PAUP*: Phylogenetic Analysis Using Parsimony (*and other methods). Version 4.0b4. Sinauer Associates, Sunderland, Massachusetts, USA.

THOMPSON J.D., GIBSON T.J., PLEWNIAK F., JEANMOUGIN F., HIGGINS D.G. 1997: The CLUSTAL X Windows interface: flexible strategies for multiple sequence alignment aided by quality analysis tools. Nucl. Acids Res. 25: 4876-4882.

ZHANG J.Y., LI Z.C. (Eds.) 1990: [Parasitology of Fishes: A Survey of Study of Parasites Found in Chinese Freshwater Fishes.] ISBN 7-03-001526-6/Q.224. (In Chinese.) 